\title{
Gender differences in language development, acquisition, comprehension, and production
}

\author{
Maulina \\ Muhammadiyah University of Kendari, Kendari, Indonesia \\ Corresponding e-mail: maulina821431@gmail.com
}

\begin{abstract}
In this $21^{\text {st }}$ century, human being is not separated with theories about gender and language which has been established from the simultaneous researches with the aim is to see a novelty on that issue. This paper summarizes findings about gender differences in language development, gender differences in language acquisition focusing on male and female brain function in acquiring language in this case English as a foreign language (EFL), gender differences in language comprehension, and gender differences in language production. The implications to teaching and learning further are presented.
\end{abstract}

Keywords: gender, language development, acquisition, comprehension, production.

\section{Introduction}

Language and gender theories at present time is not separated with human life in facing the global challenges in order to be reputed with the development, acquisition, comprehension, and production of the language in this case English as a Foreign language. The study of gender differences in conversational speech is important for several reasons. One reason is its relevance to psycholinguistics. It has been previously established that for some language tasks, different parts of male and female brains are activated for the same task (Ojemann, 1983). However, all language studies at present work with a single language production model which is being increasingly refined with modern research. In order to establish key gender differences in language production, then such models must be studied in light of a new finding in order to be valid. Another reason why language and gender study is important is because of its usefulness to linguists and psychologists in general.

Currently, there is only a weak support in favor of gender differences in language development. Duyne \& Scanlan (2012) studied about male and female's performance in a verbal and non-verbal task in integrating functional system differently with the purpose to gain the same adaptive effect. It was found that verbal control loaded on fine and gross perceptual motor functions for female, while for male it loaded on a broad undifferentiated verbal-nonverbal function. Other studies related with gender and language development have been under investigated by Kaltsa, et al (2017) about the development of four gender assignments and gender agreement in bilingual Albanian-Greek and English-Greek children as well as the exploitation of gender cues on the noun ending in real and pseudo-nouns, Huerta, et al (2016) on the academic language development and conceptual understanding via science notebooks, and Lewis, et al (2014) on the early markers of vulnerable language skill development in galactosemia. In addition, there is a popular belief that females are more advanced in language development than males.

Then, it seems to be no end to the debate over gender differences in the brain especially in relation to language acquisition, comprehension, and production. There has been much attention on studying male and female differences in acquiring language showing the solid arguments that female consistently outperforms male in multiple aspects of language acquisition (Wyk, 2016; Dabašinskienè, 2012; Spellerberg, 2011; and Nikolova, 2011). Otherwise, minor debate in language comprehension and gender differences that it needs a priority to discuss for further researchers. Therefore, it seems to be no end to the debate over gender differences in the brain. The fact that males and females have different brains is not surprising, but the implication is quite important because it means that not all brains think the same way. This simple fact might inspire and fix the notion of individualism in 
language acquisition. That males and females have a unique ability to learn more than one language is actually a well-established fact. This paper, further, will provide brief explanation and elaboration related to issues mentioned in order to present the understanding of gender differences psycho-linguistically.

\section{Discussion}

In this part, it will elaborate briefly some male and female differences in fourth issues on language mention previously as a general discussion and it will be linked with their relations to English learning. The differences are from research results found by credible researchers over the world.

\section{Gender differences in language development}

First, O'Kearney \& Dadds (2010) observe the emotion language in 303 adolescents aged between 12 and 18 years old. They apply a theoretically derived classification model to describe and assess age-dependent changes and gender differences in the semantic, referential, and causal structure of their language for emotions in response to vignette material containing the prototypical condition for anger and fear. They found that the emotion language structure in subjects is age-dependent and sensitive to gender-related "display rules" for talking about emotions and their causes. It is in line with a study recently done by conducted by Stangeland, Lundetrae, and Reikerås (2018) explore gender differences in early language proficiency and they found that Children with high language scores participate more in language activities than children with low language scores. In addition, Kuronen and Tergujeff (2018) investigate the L2 prosody development which reveals that the development in learning Swedish tonal word accent $2\left(\mathrm{H}^{*} \mathrm{LH}\right)$ provides other tonal developments towards native-like utterance intonation.

Of the researches result, male and female contribute and show different way in their language development process. It is because the superiority of females in language development may be the result of earlier maturation of the left cerebral hemisphere which is normally dominant for certain speech functions. This earlier maturation would be a good explanation why girls begin to speak earlier and that is why in English classroom female students seem to speak a lot than males as well as males and females probably have somewhat different brain structures because they have a different prenatal hormonal environment.

\section{Gender differences in FL acquisition}

Males and females have a unique ability to learn more than one language is actually a wellestablished fact. Understanding the sexual brain differences central to language acquisition may present the single most important challenge to readers especially those who pursue study at English Department and/or English Education Department, in order it turns out that the sexual basis of the brain is amenable to educational strategies to help them to recognize and sharpen the brain working. In addition, this paper is to provide a valid understanding that the sexual brain distinction between females and males can have important implications in the realm of language acquisition, in general, and SLA and FLA, in particular.

Many researches concern about sex differences in acquiring language in this case English as a foreign language and they indicate that they seem to be no end to the debate over them.

First, according to Spellerberg (2011), L3 learners (girls) as a group do less well in English than L2 learner peers (girls) that the genderrelated tendencies found in a study of factors influential in third language acquisition of English in Denmark and Greenland. Moreover, Maluch \& Kempert (2017) said that bilingual children in immigrant communities proficient both majority and minority languages in order to develop advantages in foreign language learning. Additionally, Mei Jiang, et al (2009) propose the students who start to acquire a second language (L2) in a natural way after puberty are thought to be constrained by biological age factors and to get much difficulty in experiencing native-like L2 that the research result suggest that the acculturation relates to speaking proficiency but not pronunciation.

Supporting the results above, the language acquisition is biologically bound holds that the way men talk to men is very different from the way women talk to women. These 
differences in communication style and communication strategy may result in different strengths and weaknesses in terms of language learning that might correlate with the sexual brain. Further, Celce-Murcia (2001) and Ellis (1994) view that females are faster and easier to process and communicate and that male brains contain approximately 6.5 times more gray matter related to intellectual processing than female brains, and female brains contain 10 times more white matter linked with intelligence than males do. Along the same line, identifying regional differences with brain reports that $84 \%$ of graymatter regions and $88 \%$ of white-matter regions involved with intellectual performance in women are found in the brain's frontal lobes, compared to $45 \%$ and $0 \%$ percent for males. In other words, the gray matter driving male intellectual performance is distributed throughout more of the brain.

Males and females are also different in multiple tasks. Rua (2006) asserts that "although both males and females have the same linguistic potentials as human beings, females' linguistic skills somehow seem more prone to be stimulated in order to reach higher levels of linguistic competence" (p.103). This persuasively leads us to Moir \& Jessel's (1989) claim that "brains of males and females are constructed differently, resulting in important differences in perceptions, emotional expression, priorities and behavior" ( $\mathrm{p}$. $5)$.

In women, in contrast, the left and the right hemispheres of the brain are in nonstop communication; this might explain why women are better able to recover language skills after suffering a left-brain stroke and why they tend to have better language skills while, males depend particularly on the left-hemisphere of the brain for language (Glass, 1992). As stated by Bornstein, Hahn, \& Haynes (2004), sexual dimorphism in the lateralization of language has been stronger in females, giving them the greater left hemisphere dominance on language acquisition.

Finally, considering the implication of gender differences in FLA, it provides some insights which help the FL teachers (in this case, English teachers) to teach more effectively. In other words, the biological fact that males and females have different brains, and so they use different pathways for the same tasks have implications about how to approach different sexes, their learning styles and the work they produce in the language classroom. According to Uster (2008), teachers, for instance, do not have to "keep verbal instructions too long since males might lose attention since their brain is not oriented for long speech" (p. 160). Furthermore, the teachers "must allow physical movement and physical activity for boys who mostly are physically oriented" (p. 160). He also argues that in order to develop males' social skills, teachers must increase employment of group work and pair work to help boys socialize. There are also some implications to take into account in the classroom when the characteristics of the female brain are considered. For example, teachers must support their instruction with objects to avoid too many abstractions which are favored by the male brain. To help the female brain, there must be some visual elements such as charts and written material.

\section{Gender differences in FL comprehension}

There have been many studies on gender differences in language comprehension particularly on language skills in this concern, English skills of listening speaking, reading, and writing. Taking an example of gender differences in reading comprehension, it was a research conducted by Cesiko (2017), he explores the gender differences in the reading comprehension of grade three rural learners whose mother tongue is IsiXhosa in the Eastern Cape of South Africa and he found that there was a significant difference in English reading comprehension test between boys and girls. The reading comprehension gap between boys and girls was wide in the English reading comprehension test than in IsiXhosa. According to Logan \& Johnston (2010), differences between boys and girls in areas relating to reading will be investigated as possible explanations for consistent gender differences in reading attainment. The review will examine gender differences within the following different aspects of reading: differences in behavioral and motivational factors, difference in cognitive abilities, differences in brain activation during reading and differences in reading strategies and learning styles.

The implication to teaching language (English) is that the teacher should take into the consideration the fact that more practice needs to be done when working with male students. In addition, the teacher can focus on different types of text in the 
class regardless of the students' gender. This may help learners to pave the way toward autonomy in that they can build on what they already know or what they have explicitly learned in their classroom. So, teachers should be aware of these differences by helping learners of both genders in different ways. By concentrating on learners' limitations, teachers can provide successful learning situations. Only this way can teachers handle the class efficiently and achieve the teaching goals. The teaching strategies can be in small groups or individually by using various reading texts and questions to check students processing problems through questioning and answering. Teaching learners comprehension monitoring and reading comprehension test taking strategies can help them to take a more reflective and self-directed approach to text reading to help them reduce anxiety in reading test.

\section{Gender differences in language production}

The study of gender differences in conversational speech is important for several reasons. One reason is its relevance to psycholinguistics. It has been previously established that individual differences in maintaining attention on the production processes become especially apparent when a simultaneous second task also requires intentional resources (Jongman, Roelofs \& Meyer, 2014). However, all language studies at present work with a single language production model which is being increasingly refined with modern research. Another reason why a conversational study is important that is its usefulness to linguists and psychologists in general. For example, language acquisition model is assisted through the understanding of how male and female speakers use language. Furthermore, a research done by Singh (2008) shows that male speech is lexically richer and phrases used tend to be longer. Female speech, on the other hand, contains shorter sentence structures, is more repetitive in its use of lexical items, uses nouns and pronouns interchangeably, and is dynamic using more verbs.

\section{Conclusion}

The studies mostly show that males and females do indeed use language in different ways. The evidence of sex differences in language development, acquisition, and comprehension are too tenuous and self contradictory to justify any claims that one sex is superior to the other. Boys are verbally more aggressive and their language shows a greater interest in space quantity, and physical movement than does the girls' language. Both sexes biological and environmental differences involved in language process.

\section{References}

Bornstein, M. H., Hahn, C. H., \& Haynes, O. M. (2004). Specific and general language performance across early childhood: Stability and gender considerations. First Language, 24, 267-304. http://dx.doi.org/10.1177/01427237040456 81

Celce-Murcia, M. 2001. Teaching English as a second or foreign language. London: Cengage Learning Ltd.

Ellis, R. 1994. The study of second language acquisition. Oxford: Oxford University Press.

Stangeland, E.B., Lundetræ, K., \& Reikerås,E. (2018). Gender differences in toddlers' language and participation in language activities in Norwegian ECEC institutions. European Early Childhood Education Research Journal, 26:3, 375-392, DOI: 10.1080/1350293X.2018.1463905

Lewis, F. M., Coman, D. J., \& Syrmis, M. (2014). Early markers of vulnerable language skill development in galactosaemia. Early Child Development and Care, 184:12, 1787-1799, DOI: $10.1080 / 03004430.2013 .878712$

Glass, L. 1992. He says, she says: Closing the communication gap between the sexes. New York: G.P. Putnam's Sons.

Duyne, H. J. V., \& Scanlan, D. (2012). Gender differences in the development of the regulatory function of language. The Journal of Genetic Psychology, 128:1, 17-26, DOI: 10.1080/00221325.1976.10533967

Dabašinskienè, I. (2012). Gender Differences in Language Acquisition: A Case Study of Lithuanian Diminutives. Journal of Baltic Studies, 43:2, 177-196, DOI: 10.1080/01629778.2012.674795

Wyk, J.V., Mostert, M.L., \& Hui, S.K.F. (2016). The influence of mother tongue and gender on the acquisition of English (L2): The case of Afrikaans in Windhoek schools, Namibia. Cogent Education, 3:1, DOI: 10.1080/2331186X.2016.1210997

Maluch, J.T \& Kempert, S. (2017). Bilingual profiles and third language learning: the 
effects of the manner of learning, sequence of bilingual acquisition, and language use practices. International Journal of Bilingual Education and Bilingualism, DOI: 10.1080/13670050.2017.1322036

Spellerberg, S. M. (2011). L3 English acquisition in Denmark and Greenland: gender-related tendencies. International Journal of Multilingualism, 8:3, 155-188, DOI: 10.1080/14790718.2011.578747

Cekiso, M. (2017). Gender differences in the reading comprehension of grade three rural learners in South Africa. International Journal of Educational Sciences, 13:2, 247 254 ,

DOI:

10.1080/09751122.2016.11890458

Huerta,M., Tong, F, Irby, B.J., \& Lara-Alecio, R. (2016). Measuring and comparing academic language development and conceptual understanding via science notebooks, The Journal of Educational Research, 109:5, 503-517,

DOI: 10.1080/00220671.2014.992582

Kaltsa, M., Prentza, A, Papadopoulou, D., \& Tsimpli, I.M. (2017). Language external and language internal factors in the acquisition of gender: the case of Albanian-Greek and English-Greek bilingual children. International Journal of Bilingual Education and Bilingualism, DOI: 10.1080/13670050.2017.1385591

Jiang, M., Green, R.J., Henley, T.B., \& Masten, W.G. (2009). Acculturation in relation to the acquisition of a second language. Journal of Multilingual and Multicultural Development, 30:6, 481-492, DOI: $10.1080 / 01434630903147898$

Kuronen, M \& Tergujeff, E. (2018). Second language prosody and its development: connection between different aspects. The Language Learning Journal, DOI: 10.1080/09571736.2018.1434228

Moir, A., \& Jessel, D. 1989. Brain sex: The real difference between men and women. New York: Dell Publishing.

Nikolova, O.R. (2011). Students' Gender and Ability Levels Impact on the Acquisition of Two French Verb Tenses. Roeper Review, 33:2, 121-133, DOI: 10.1080/02783193.2011.554159

O'Kearney, R \& Dadds, M. (2010). Developmental and gender differences in the language for emotions across the adolescent years. Cognition and Emotion, 18:7, 913938, DOI: 10.1080/02699930341000356

Rua, P. L. 2006. The sex variable in foreign language learning: An integrative approach. Porta Linguarum, 6, 99-114.

Logan, S \& Johnston, R. (2010). Investigating gender differences in reading. Educational Review, 62:2, 175-187, DOI: 10.1080/00131911003637006

Jongman, S.R., Roelofs. A., \& Meyer, A.S. (2014). Sustained attention in language production: An individual differences investigation. The Quarterly Journal of Experimental Psychology, 68:4, 710-730, DOI: 10.1080/17470218.2014.964736

Sighn, S. 2008. A pilot study on gender differences in conversational speech on lexical richness measures. University of Exeter

Spellerberg, S. M. (2011). L3 English acquisition in Denmark and Greenland: gender-related tendencies. International Journal of Multilingualism, 8:3, 155-188, DOI: 10.1080/14790718.2011.578747 